\title{
La enseñanza del arte en la escuela de historia de la Universidad Autónoma de Zacatecas
}

\section{Teaching art in the history school from the Autonomous University of Zacatecas Laura Gemma Flores García ${ }^{a}$}

\begin{abstract}
:
In this essay a brief review is made of how Art History has been taught in the School of History of the Autonomous University of Zacatecas and how its importance has diminished despite the required local needs, as the student must be prepared to meet the needs of a UNESCO World Heritage City.
\end{abstract}

Keywords:

Art, Art History, Art Teaching

Resumen:

En este ensayo se hace una breve reseña de cómo se ha impartido la Historia del Arte en la escuela de Historia de la Universidad Autónoma de Zacatecas y cómo ha ido mermando su importancia pese a las necesidades locales requeridas en tanto que el estudiante debe estar preparado para atender las necesidades de unai Ciudad Patrimonio de la Humanidad nombrada por la UNESCO.

Palabras Clave:

Arte, Historia del Arte, Enseñanza del arte

\section{INTRODUCCIÓN}

En 1994, la línea de Historia del Arte integrada en el tronco común de la carrera de Historia perteneciente al eje de Humanidades de la Universidad Autónoma de Zacatecas, consistía en un grupo de asignaturas diseñadas para elaborar discursos contextualizados en el campo de la historia occidental, la antropología y su relación con la arqueología. A partir de agosto del año 1994 en que se concedieron los cursos de arte a la autora de este artículo, se diseñaron tres módulos consecutivos pero trasversales de la enseñanza del arte: la primera carta programática incluyó los elementos formales de la Historia Occidental del Arte, desde la época prehistórica hasta el Renacimiento, fundamentada en los cánones clásicos que se repetían desde el arte grecolatino hasta las rupturas de las vanguardias; aquí se revisaron: Prehistoria, Arte del Medio Oriente, Arte Egipcio, Arte Cretense, Arte Griego, Romano, Arte Medieval y Renacimiento. El segundo curso, enfocado a la Historia del Arte en México retomó el arte Renacentista trasplantado en México durante el siglo XVI y las primeras manifestaciones arquitectónicas y pictóricas del arte español, italiano y flamenco que replicaron los mismos principios formales en América, aunque adquiriendo una personalidad propia por su sincretismo con el arte prehispánico. En este segmento se revisaron expresiones del arte a nivel nacional por siglos (XVI, XVII y XVIII) y por zonas (zona sur, altiplano, centro norte, centro occidente, etcétera). Esta segunda secuencia comprendió simultáneamente el manierismo, el barroco, el neoclasicismo y el romanticismo. La tercera asignatura comprendió desde el impresionismo y las primeras vanguardias para hacerlo coincidir con el Arte Regional. Lo novedoso de este planteamiento fue que a partir del contacto con los museos de Zacatecas como el Museo Pedro Coronel, el Museo Rafael Coronel, el Museo Goitia, el Museo de Guadalupe, se analizaron las vanguardias artísticas; y las visitas a sitios locales fueron mostrando al estudiante el complejo de las manifestaciones artísticas hasta nuestra época. Se visitaron sitios cercanos como: Trancoso, Tacoaleche, Aguascalientes, Malpaso, Jerez y Fresnillo y en cada uno se fue localizando un estilo arquitectónico perteneciente a cierta época y etapa constructiva. Se trabajó por autores y se revisaron artes menores. El trabajo de campo de los alumnos fue definitivo a partir de lo cual se logró develar los signos del arte.

\footnotetext{
a Autor de Correspondencia, Universidad Autónoma de Zacatecas. Investigadora Nacional de México, https://orcid.org/0000-0002-74054883, Email: ars.flores@gmail.com
} 
Las reformas recientes a estos tres módulos se generaron a partir de 2004 en que las materias de arte se complementaron con otras y después se volvieron opcionales (2011), lo cual dejó en un estado de ausencia total esta importante disciplina. Este hecho lleva a replantear su incorporación, pues el estudio del arte se ha desintegrado de su esencia, mezclándose con exposiciones generalizadas como: cultura y patrimonio. El debate es esbozar hasta qué punto el arte y la historia del arte deben ser estudiadas como materias exentas o revisadas desde sus propias teorías, metodologías y de análisis.

\section{Un poco de historia*}

Desde sus orígenes - de 1987 a 1992 - bajo la dirección del maestro Veremundo Carrillo, la política de la escuela de historia fue impulsar su fortalecimiento mediante un sistema modular que promovía la interdisciplinariedad $y$, debido al escaso número de profesores se favoreció la problematización a diferencia del modelo departamental organizado por asignaturas. El plan de estudios se caracterizó por un tronco común y posteriormente los alumnos decidían una especialidad. La carrera humanística se separó en disciplinas (Historia, Filosofía y Letras). Tenía una duración de cinco años y los dos primeros consistían en el tronco común ramificándose después en áreas de especialización (Historia, Filosofía o Letras).

En 1990 se implementó un segundo plan de estudios que pretendía remediar vacíos del primer programa. En 1991 se realizó el II Foro Interno donde el objetivo fue un revisionismo del Plan de Estudios. En 1992 hubo cambio de director en la ya Facultad de Humanidades. El Mtro. Marcelo Sada Villarreal inició su desempeño con un nuevo edificio que fue gestionado por la anterior administración. Se inauguró la Maestría en Estudios Novohispanos con la contratación de profesores externos, algunos egresados de El Colegio de Michoacán. Otra iniciativa fue concretar el contacto con diferentes municipios para dar vida a los primeros foros que se enfocaron en reescribir historias municipales y la publicación de monografías como fue el caso de Vetagrande, Pinos, Fresnillo Zac. entre otras. Respecto al nuevo plan de estudios en 1994 en el caso de la Licenciatura en Historia se intentó romper con el eurocentrismo, centrando su atención en historias generales tales como América Latina, Asia y África, además de la historia de los Estados Unidos de Norteamérica y las tres historias de arte arriba mencionadas. También se atendió a los estudiantes en el manejo de computadoras, incorporando herramientas que coadyuvaron a la interpretación histórica (hermenéutica, filología y semiótica). En 1996, inició actividades el área de especialización en arqueología, por lo que en ese año la Universidad ya contó con cuatro licenciaturas del área de Humanidades. En 1997, se fundó la Maestría en Humanidades-Área Historia y se promovió una Maestría en Humanidades para la actualización del personal docente de las preparatorias. En 1998, se llevó a cabo el proceso de evaluación de los CIEES; organismo que imprimió 15 recomendaciones a la Licenciatura en Historia. En 1999 la Facultad de Humanidades modificó su formato, descartó el tronco común e incrementó el número de materias de las áreas de especialización. El área de Historia organizó por primera vez reuniones con egresados y empleadores y revisó planes de universidades nacionales y extranjeras. Se aumentó el número de horas-aula de 4 a 5 horas. Entre las materias quedaron las -Introducciones Historiografías Universales -Historiografías Mexicanas Historias Universales -Historias de México -Historias Generales -Historias del arte.

A partir del año 2000 la Unidad Académica de Historia, conformada por los programas de licenciatura y maestría, inició una carrera independiente de otras disciplinas, por lo cual se conformó una coordinación y una dirección, así como responsables de programa para licenciatura y maestría. Entre agosto y septiembre de 2000 , el director y los responsables de los programas prepararon un plan de desarrollo y operativo anual de la Unidad y se concretaron foros y congresos en colaboración con otras identidades locales. Desde mayo del 2003 la planta docente del Programa Educativo (PE) de la UAH con la asesoría de la responsable del Departamento de Docencia Mtra. Raquel Jiménez Díaz, procedió a actualizar el Plan de Estudios General dando como resultado la creación de un nuevo modelo educativo, constituyéndose - de esta manera - la Licenciatura en Historia en el Programa Piloto de lo que fue conocido como el Modelo UAZ Siglo XXI. Se planificó un estudio comparativo de veintiún planes de estudios de Licenciatura en Historia con otras universidades nacionales a fin de ubicar la situación del plan vigente y proponer la Reforma del Plan de Estudios 2004. De aquí resultó la estructura en áreas (común, básica, disciplinar, optativa); ejes terminales (docencia, investigación, extensión), y ejes transversales (género, democracia, derechos humanos, ecología, globalización, desarrollo sustentable); con un $58 \%$ de las asignaturas optativas y el servicio social integrado a la currícula. Durante el periodo 2004-2008 el desarrollo y funcionamiento de cada programa educativo de la Unidad Académica de Historia fue dirigido por los responsables de cada uno de los programas. En el 2005 se fusionaron los programas de la Maestría en Historia y el Doctorado en Historia Colonial, conformando la Maestría-Doctorado en Historia. Durante este periodo, tanto la licenciatura como el posgrado fueron evaluados por los CIEES. En este Plan se consideraron los ejes de especialización en Historia del Arte con las siguientes asignaturas optativas: Apreciación Estética. - Historia de los estilos artísticos. Historiografía general del arte. - Estética. - Iconografía e iconología. - Teoría del arte.

Las optativas generales incluyeron: Historia del Arte Antiguo, -Historia del Arte Medieval, - Historia del

\footnotetext{
* Agradezco a la Dra. Lidia Medina Lozano haber puesto en mis manos los documentos relativos a las dos reformas a Planes de Estudios de la carrera de Historia (2004 y 2011).
} 
Arte Renacentista, - Historia del Arte Barroco - Historia del Arte contemporáneo. Mientras que para Historia del Arte en México se estructuraron las siguientes materias: Historia del Arte Virreinal Mexicano, Historia del Arte del México Independiente, Historia del Arte del México Contemporáneo, Historia del Arte Regional, Historia de las ciudades e Historia y apreciación del cine.

Para la Reforma del Plan de Estudios 2011 se estipularon los siguientes perfiles para el historiador del arte: Conocimiento: Adquiere una visión general de los diferentes procesos histórico-artísticos, en los ámbitos teórico-metodológicos e historiográficos.

Competencias: Desarrollo crítico y analítico de la producción artística en sus distintos lenguajes (arquitectura y urbanismo, escultura, pintura, fotografía, cine, música, artes decorativas y suntuarias) representativos de cada época de la historia.

\section{Problemática}

Visto este panorama general de la historia del actual Programa de Licenciatura en Historia mencionaremos una lista de Instituciones educativas y culturales que ofrecen actividades artísticas en o desde los municipios de Guadalupe y Zacatecas, * y para las cuales la Universidad Autónoma de Zacatecas debe estar preparada a fin de formar especialistas en historia del arte, creación artística, gestión cultural y/o sus distintas ramas derivadas. Entre todas esas entidades se cuentan:

1.- Centros pedagógicos para educación media como: tecnológicos, bachilleres, escuelas, institutos, liceos y la propia Universidad Autónoma de Zacatecas con sus 13 programas de Preparatorias. Estos centros, al menos los que incluyen en su currícula cuestiones de arte son públicos, privados y de colaboración mixta (16 en total). 2.- Centros de educación superior como universidades públicas y privadas entre las que se cuentan: la universidad del estado, universidades privadas, Pedagógica Nacional, Escuela Normal Superior y otras privadas (en total 13).

3.- Instituciones de Gobierno que imparten oferta artística: casas municipales, centros, institutos, talleres $\mathrm{y}$ redes (en total 10).

4.- Talleres independientes (5).

5.- Instituciones privadas (7)

6.- Museos y Galerías (21)

Estas 57 entidades, además de las carreras diversas de las nuevas universidades que se han creado a partir de este estudio $(2009){ }^{\dagger}$ requieren y precisan de especialistas formados en arte, en historia, teoría, difusión, divulgación y las diversas ramas del arte. Con las nuevas reformas la Universidad Autónoma de Zacatecas forma en promedio dos a tres estudiantes por

\footnotetext{
* María de Lourdes Almaraz, Susana Chávez Noriega et. al. Directorio de las Instituciones que ofrecen actividades artísticas en los municipios de Guadalupe y Zacatecas, Licenciatura en Intervención educativa, Universidad Pedagógica Nacional Unidad 321-Zacatecas, Enero 2006. Este trabajo fue completado con la Agenda Cultural del
}

generación que escasamente han tomado uno o dos cursos optativos de arte durante toda su carrera.

Actualmente existe un Cuerpo Académico en la UAZ titulado "Teoría, historia e interpretación del Arte" que ha intentado sostener y complementar una formación informal a través de Diplomados de Arte. En 2006 se brindó un Diplomado de Historia del Arte Mexicano al que se inscribieron un promedio de 50 personas; más tarde se ofreció un Curso-Taller de Arte Universal en el que se inscribieron un promedio de 30 personas y uno de Arte y estética al cual ingresaron 50 personas. Los tres fueron impartidos por la UAZ en el marco de Educación Continua de la Coordinación de Vinculación. Posteriormente se han impartido bianualmente los Diplomados "Campos multidisciplinares del Arte" que para el año 2020 llegaron a su quinta edición con el título "El arte frente a la (im) posibilidad del dolor" vinculando las experiencias estéticas relacionadas con la pandemia.

Si se observa a nivel local cuántos centros educativos de la región centro-occidente tienen demanda real y potencial para ingresar o emplear historiadores del arte se constata que no es suficiente la formación requerida para atender la oferta cultural y artística que cada día crece en Zacatecas.

\section{Conclusiones}

No es este el sitio para disertar un tema que ha llenado siglos de bibliotecas desde que se fundara la emblemática Biblioteca de Alejandría, la más grande en el mundo erigida en el siglo III por Ptolomeo y que recientemente refundó la UNESCO (2002). Todo lector ha tenido al menos una vez en su vida contacto con el arte, ya sea voluntaria o tangencialmente a través de la asistencia a un museo, un concierto, una obra de teatro. Han tocado quizás una escultura, admirado una obra maestra en alguna producción cinematográfica, escuchado un concierto de ópera. No es discutible la importancia del arte para sensibilizar al hombre y contactarlo con su yo más profundo y con las respuestas a sus perennes preguntas sobre su existencia en el orbe. En esta ocasión sólo es preciso plantear la pregunta de ¿cómo siendo Zacatecas ciudad patrimonio de la humanidad y habiendo sido declarada doblemente por la UNESCO patrimonio de la humanidad ahora con el Camino Real de Tierra Adentro; contando con acervos impresionantes de colecciones nacionales e internacionales de pintura, escultura, artes menores, grabados, óleos con multitud de técnicas; albergando el Museo de Guadalupe una de las más grandes pinacotecas de América Latina y poseyendo uno de los más importantes museos de Arte abstracto de toda América Latina (Arte Abstracto Manuel Felguérez), se

Instituto Zacatecano de Cultura, Gobierno del Estado de Zacatecas, Marzo 2009. Y el Sistema de Información Cultural (SIC) https://sic.gob.mx/lista.php?table=museo\&estado_id=32\& municipio_id=-1 (2019).

† A 17 años de este estudio las necesidades han aumentado. 
haya decidido reducir a cursos optativos tan importante enseñanza, sin avizorar que este tema es potencialmente rentable y de explotación para los egresados de la licenciatura en historia? Sin duda habrá que replantear una Reforma Educativa que sostenga el precedente de las generaciones formadas en los años 90 que atienden múltiples necesidades. Es preciso remarcar que el arte también es rentable, vendible, redituable; pero para ello hay que seguir mostrando creativamente cómo se puede obtener un recurso de un patrimonio tangible que espera por mentes más lúcidas y conocedoras de lo que nos rodea. Los programas de posgrado en humanidades de la UAZ, han demostrado que hay una gran cantidad de alumnos que se acercan esperando desarrollar temas relativos al arte, ya sea local, estatal, regional o mundial. Es necesario sentar las bases para que no aspiren a un posgrado sin conocimientos básicos sobre el arte, que permitan desarrollar investigaciones a fondo, revisar los acervos de los museos, diseñar catálogos, replantear curadurías en los museos, crear nuevos circuitos turísticos, etc. Todo ello, solo lo permite el conocimiento profundo del arte. 